\title{
Cleft lip and palate: Epidemiology and etiology
}

\author{
Deniz A Oner ${ }^{1 *}$, Hakki Tastan ${ }^{2}$ \\ ${ }^{1}$ Afyonkarahisar Health Sciences University, Atatürk Vocational School of Health Services, Afyonkarahisar, Turkey \\ ${ }^{2}$ Department of Biology, Faculty of Science, Gazi University, Ankara, Turkey
}

\begin{abstract}
Cleft lip and palate are considered as one of the most common birth defects that result in medical, psychological, and social problems in affected individuals and their families. It has a complex etiology in which both genetic and environmental factors play a role. Risk factors such as vitamin deficiency, especially folic acid deficiency, and maternal smoking, alcohol consumption, drug use, and chemical exposure have been associated with cleft lip and palate development.
\end{abstract}

Identifying the factors contributing to cleft lip and palate etiology is important for preventing their development and for taking necessary measures. This article, which is based on the review of national and international literature, is important as it serves as a source for researchers and clinicians focusing on cleft lip and palate.

\section{Introduction}

Cleft lip and palate are hereditary diseases in which environmental and genetic factors together play a role, leading to different clinical outcomes. Generally, cleft lip and palate cases are divided into two groups: cleft lip with/without cleft palate $(\mathrm{CL} / \mathrm{P})$ and isolated cleft palate (CP). Depending on the presence of certain anomalies, the cases are also classified as syndromic and non-syndromic (nsCLP) clefts.

Approximately $70 \%$ of $\mathrm{CL} / \mathrm{P}$ patients and $50 \%$ of $\mathrm{CP}$ patients are non-syndromic. In the remaining patients, a wide range of malformation syndromes can manifest, including chromosomal anomalies and teratogens as well as more than 500 defined Mendelian syndromes [1-3].

Children born with cleft lip and palate develop complications such as nutritional difficulties, respiratory failure, and hearing and speech difficulties. In addition to health problems, affected individuals face long-term social difficulties such as acceptance. Even if surgical intervention is performed in the early period, deformities due to scarring and abnormal facial development cause persistence of functional and psychosocial problems throughout the patient's life.

It is necessary to understand the factors underlying these defects in order to foresee the long-term course of development of individuals with a cleft lip and palate that should be treated using a multidisciplinary approach including a plastic surgeon, otolaryngologist, speech therapist, audiologist, orthodontist, psychologist, social worker, and nurse. Epidemiological studies and observational reports have shown that folic acid supplements taken by the mother before pregnancy have a protective effect in reducing the incidence of cleft lip and palate, whereas smoking and alcohol consumption before pregnancy increase the risk of cleft lip and palate formation [4-6].

The aim of this study was to examine the epidemiology of lip and cleft palate and to evaluate the factors that may lead to their development. For this purpose, national and international literature was reviewed.

\section{Epidemiology of cleft lip and palate}

Cleft lip and cleft palate are one of the most common birth anomalies that may occur due to environmental factors and socioeconomic conditions as well as variability across geographic origin, race, and ethnic groups. CL/P prevalence is highest in the Asian and American populations and lowest in African populations. The gender distribution of cleft lip and palate is not equal in general. The incidence of $\mathrm{CL} / \mathrm{P}$ is 2 times higher in men than in women, whereas that of $\mathrm{CP}$ is higher in women [2].

$\mathrm{CL} \pm \mathrm{P}$ incidences were reported in a study conducted by the International Perinatal Database of Typical Orofacial Clefts established in 2003 through the Human Genetics Program of World Health Organization (WHO). On the basis of the records evaluated according to geographical regions, $\mathrm{CL} \pm \mathrm{P}$ incidences were determined in Japan, Mexico, Western Europe, Canada, the United States, Australia, British Isles, Eastern Europe, United Arab Emirates, South Mediterranean Europe, and South Africa; the incidence was the highest in Japan and the lowest in South Africa (Figure 1) [7].

The generally accepted incidence of $\mathrm{nsCL} / \mathrm{P}$ across the world is 1 in 1000 births. However, the incidence varies depending on ethnic background, geographical origin, and socioeconomic level. The incidence of $\mathrm{nsCL} / \mathrm{P}$ is 0.3 in 1000 births in African populations, 0.71.3 in 1000 births in European populations, 1.4-2.1 in 1000 births in Asian populations, and 3.6 in 1000 births in American populations [8].

The prevalences of $\mathrm{nsCL} / \mathrm{P}$ and $\mathrm{nsCP}$ in Europe according to EUROCAT registration data, which is widely used in the classification of congenital malformations, are presented in figure 2 [9].

${ }^{\star}$ Correspondence to: Deniz Aslar Oner, Afyonkarahisar Health Sciences University, Atatürk Vocational School of Health Services, Afyonkarahisar, Turkey, Tel: +90 536 2774846; E-mail: denizaslar@gmail.com

Key words: cleft lip and palate, epidemiology, etiology

Received: June 11, 2020; Accepted: June 29, 2020; Published: July 03, 2020 


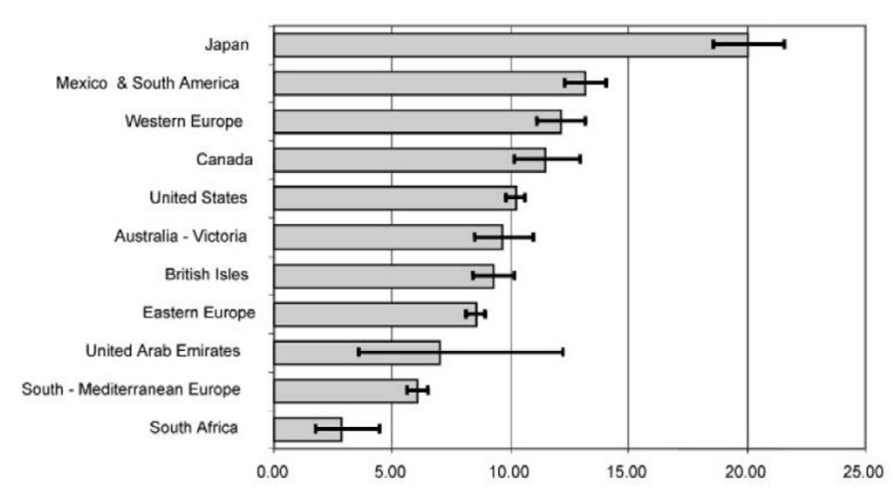

Figure 1. Prevalence of CL/P by geographical area (per 10,000)

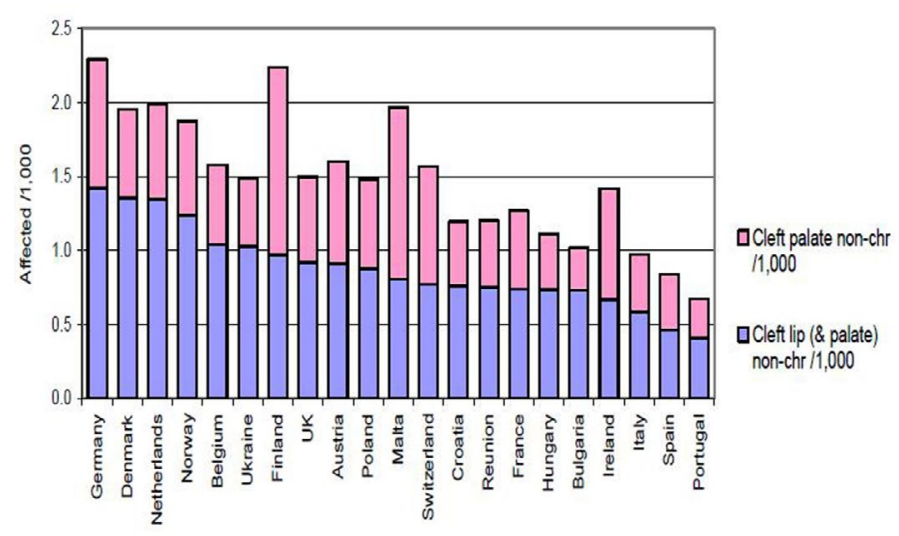

Figure 2. Prevalence of non-syndromic (CL(P) and $\mathrm{CP})$ in Europe

The multifactorial inheritance model, which involves the interaction of genetic and environmental factors, is a good example for the epidemiological findings of nsCL/P. The risk of cleft lip and palate in a family varies depending on many factors. Risk factors and factors increasing the severity of cleft lip and palate are determined based on the number of family members with cleft lip and palate (positive family history), degree of relationship, gender of the affected individual, and type of cleft. If there is a child with cleft lip and palate in a family, the risk that the next child will be affected is $2 \%-5 \%$; however, the risk increases to $10 \%-12 \%$ if the family has more than one child with cleft lip and palate. If a recurrent syndrome is also present in the family, the risk increases to $50 \%$. Studies have shown that the prevalence of $\mathrm{nsCL} / \mathrm{P}$ is significantly higher in maternal twins $(40 \%-60 \%)$ than in fraternal twins (3\%-5\%) $[8,10]$.

Due to its unique geographical location that connects Middle East, Europe, and Asia, Turkey has been exposed to a high degree of immigration. Variability, along with the increase, in population has led to the formation of a complex heterogeneous ethnic picture in Turkey and has resulted in a diverse set of important genetic variations in the current population. Thus, epidemiological studies on cleft lip and palate in Turkey are important for establishing a resource for researchers and clinicians.

Ulucan et al. [11] was aimed to analyse the distribution of Turkish children patients with nsCL/P according to the geographic regions and analyse the possible geographic and environmental factors which can be considered in the aetiology of the anomaly. When regional conditions were researched, it was shown that the eastern parts of Turkey have a relatively higher number of NSCL/P patients than other regions. The ratio of the boys to girls was determined as $154 / 136$. They explained that because of agriculture and animal husbandry are the main sources of income in the eastern parts of Turkey, the people living in this region are probably exposed to a greater cumulative burden of pesticides and chemicals from the soil or from the animals feeding in these regions. In addition, several studies have shown that exposure to certain chemicals like glycol ether, which is a compound found in domestic and industrial products, organic solvents like xylene, toluene, pesticides and lead has been reported to increase the orofacial cleft.

Studies conducted in Turkey have presented statistical data through retrospective evaluation of patients admitted to hospitals for treatment. A study was conducted including 17,259 births between 1988 and 2005 in the Gazi University Department of Obstetrics and Gynecology to determine the total frequency of malformations, types of malformations, incidences of isolated and combined forms, and distribution of malformations by maternal age and gender. A total of 205 anomalies were detected in the study. On the basis of these anomalies, fetal birth rate with congenital malformation was found to be $1.18 \%$. The rate of presence of any congenital malformation was $1.21 \%$ in boys and $1.15 \%$ in girls. Furthermore, the study results showed the prevalence of cleft lip to be $2.43 \%$ and that of cleft palate to be $1.95 \%$.

A study was conducted at the Hacettepe University Faculty of Medicine in 2004 to identify comorbid malformations and syndromes in cleft lip and palate patients; 1,229 patients who were followed up and treated for cleft lip and palate were included in the study. Of them, 793 (64.4\%) patients had both cleft lip and palate and 436 (35.6\%) had CP. Comorbid malformations were found in 91 (11.4\%) of the 793 patients with cleft lip and palate and $60(13.7 \%)$ of the 436 patients with CP. Extracranial skeletal system malformations were concluded to be the most common malformations [12].

Another study was conducted in Turkey at the Selçuk University Meram Medical Faculty in 2012. The purpose of this study was to investigate the incidence and type of accompanying congenital malformations in infants with $\mathrm{CP}$ and $\mathrm{CL} / \mathrm{P}$ born in Konya region. A total of 121 infants diagnosed with $\mathrm{CP}$ and $\mathrm{CL} / \mathrm{P}$ were included in the study and evaluated in detail for congenital anomalies. The results showed that at least one other malformation was present in 80 infants with cleft lip and palate. The most common congenital malformation was congenital heart disease, followed by head and neck anomalies [13].

\section{Etiology of cleft lip and palate}

Cleft lip and palate are considered as one of the most common birth defects that result in medical, psychological, and social problems in affected individuals and their families. They have a complex etiology in which both genetic and environmental factors play a role. Risk factors such as vitamin deficiency, especially folic acid deficiency, and maternal smoking, alcohol consumption, drug use, and chemical exposure have been associated with cleft lip and palate development.

\section{Vitamin deficiency}

Epidemiological studies and observational reports have shown that folic acid supplements taken by the mother before pregnancy have a protective effect in reducing the incidence of cleft lip and palate. The decrease in the risk of $\mathrm{CL} / \mathrm{P}$ formation with folic acid supplements has been calculated as $69 \%-76 \%$ in animal experiments, whereas it is $18 \%$ $50 \%$ in humans $[5,9]$. 
In the United States, folic acid supplementation has become mandatory as of January 1, 1998, to reduce the occurrence of neural tube defects. Yazdy et al. [14] compared the effect of folic acid supplementation on orofacial cleft prevalence between 45 states of the United States and in the Colombian region; they used birth certificate data to compare the prevalence of cleft lip and palate before and after birth. According to the study results, folic acid supplementation in the United States was associated with a decreased prevalence of cleft lip and palate.

Furthering our knowledge regarding the role of nutrition in the pathogenesis of orofacial clefts is important for the prevention of orofacial clefts in the future. In North America, where the use of folic acid-enriched cereals has been made mandatory since 1990, the numbers of children born with CL/P and CP have decreased by $5 \%$ and $12 \%$, respectively [15]. Badovinac et al. [16] conducted a meta-analysis to demonstrate that the prevalence of $\mathrm{nsCL} / \mathrm{P}$ was different between mothers who used folic acid supplements during pregnancy and those who did not. They showed that the use of folic acid supplements during pregnancy has a protective effect against cleft lip and palate development at birth.

In a study conducted by Chevrier et al. [17] 15 groups were formed based on the amount of folic acid taken during pregnancy, and the daily doses were calculated accordingly. Based on the obtained results, it was seen that control mothers had a higher nutritional folic acid intake than patient mothers. Therefore, it was concluded that dietary folic acid intake reduces the risk of $\mathrm{CL} / \mathrm{P}$.

In addition to low serum folate levels in patients with cleft lip and palate, it has been reported that low B6 and B12 levels detected after pregnancy increase the risk of cleft lip and palate. Munger et al. investigated the relationship between $\mathrm{nsCL} / \mathrm{P}$ and maternal vitamin B6 levels in Philippines. Their results showed that vitamin B6 levels were lower in mothers who had children with nsCLP than in control mothers and that the risk of giving birth to infants with cleft lip and palate was higher in the former [18].

\section{Maternal smoking}

According to WHO data, tobacco consumption among women of reproductive age has increased in many countries [19]. Especially during pregnancy, maternal smoking plays a role in the pathogenesis of nsCLP. Cigarette smoke, comprising approximately 4,000 chemical components, including aromatic and heterocyclic amines that lead to metabolic activation and DNA damage, affects genes, thereby causing alterations in metabolic pathways and leading to the development of cleft lip and palate [20].

In a study by Honein et al., nsCLP risk was found to be 1.3-times higher in children of smoking mothers than in those of non-smoking mothers $(95 \% \mathrm{CI}=1.0-1.6)$ [21]. In a study conducted by Martelli et al. [22] on 843 mothers who smoked during the first trimester and had children with CL/P and 676 control mothers, a significant relationship was found between $\mathrm{CL} / \mathrm{P}$ formation in infants and maternal smoking. $\mathrm{CL} / \mathrm{P}$ risk was 2 times higher in children of smoking mothers than in those of non-smoking mothers.

\section{Maternal alcohol consumption}

In humans, alcohol has been found to be teratogenic, and this is clearly demonstrated in fetal alcohol syndrome [23]. Alcohol consumption is known to reduce serum folate levels while inhibiting folate metabolism [24,25]. Several studies have identified a positive relationship of cleft lip and palate formation with maternal alcohol consumption, whereas no such relationship has been found with low levels of maternal alcohol consumption during pregnancy [26].

Molina-Solana et al. showed a relationship between maternal alcohol consumption and cleft lip and palate formation; they determined the risk of cleft lip and palate formation in babies to be 1.28 (95\% CI $=0.98-1.66)$ [27]. In a study including 192 mothers who had children with cleft lip and palate, Bille et al. [28] reported that, although not statistically significant, alcohol consumption in the first trimester increased the risk 1.11 times.

One possible mechanism for alcohol-induced embryonic malformations is the inhibition of retinoic acid synthesis by ethanol during embryogenesis. High alcohol consumption levels cause inhibition of the production of retinoic acid necessary for cranial neural crest development [29].

\section{Maternal drug use}

Epidemiological studies have shown that maternal drug use at high doses during pregnancy increase the risk of giving birth to infants with cleft lip and palate. Maternal use of vasoactive drugs, such as aspirin and ibuprofen; antiepileptic drugs; and drugs used in the treatment of acne, psoriasis, arthritis, and cancer increase the risk of cleft lip and palate at birth $[30,31]$.

Pradat et al. [32] based their study on the MADRE database generated using the data of mothers using corticosteroids in the first trimester of pregnancy and showed a significant correlation between the regular use of corticosteroids and cleft lip and palate formation in babies; moreover, CLP risk was calculated to be 2.59 in babies. In conclusion, women who want to have babies need to be careful and conscious while using drugs during pregnancy.

\section{Maternal exposure to chemicals}

Of all expectant mothers, $27.59 \%$ are exposed to chemicals in the first trimester of pregnancy; $11.30 \%$ of these mothers come into contact with cleaning products, $7.83 \%$ with pesticides, and $6 \%$ with cosmetics [33]. Garlantézec et al. [34] showed that exposure to chemicals is associated with cleft lip palate formation as harmful solvents are present in cleaning agents, cosmetics, and other products. The incidence of cleft lip and palate was higher in children of mothers working in professions such as hairdressing, agriculture, and manufacture of leather or shoes (where workers are exposed to lead and aliphatic acids) [35]. Chevrier et al. [36] investigated the risk of nsCLP in the children of mothers occupationally exposed to organic solvents in the first trimester of pregnancy. Their study results showed that exposure to organic solvents during pregnancy may play a role in cleft lip and palate etiology.

\section{Other syndromes accompanying cleft lip and palate}

Approximately $70 \%$ cases of cleft lip and palate are non-syndromic. The etiology of syndromic clefts, constituting approximately $30 \%$ of the cases, includes more than 300 defined Mendelian syndromes, teratogens, and uncategorized syndromes [1].

Tunçbilek conducted a study in Turkey on patients who presented to the Hacettepe University for cleft lip and palate treatment and reported the statistical results. A total of 206 additional malformations requiring follow-up or treatment were detected in 151 of 1,229 patients included in the study. On examining these malformations according to the affected organ system, extracranial skeletal system malformations were found to be the most common group of malformations. Furthermore, 55 of the 1,229 patients were found have syndromic cleft lip and palate (Table 1); examination of these patients showed that 
Table 1. Distribution of syndromes detected in patients

\begin{tabular}{|l|c|}
\hline Syndromes & Numbers \\
\hline Pierre Robin syndrome & 15 \\
\hline Van der Woude syndrome & 7 \\
\hline Ectrodactyly, ectodermal dysplasia, and cleft lip/palate syndrome & 4 \\
\hline Down syndrome & 2 \\
\hline Oro-cranio-digital syndrome & 2 \\
\hline DiGeorge syndrome & 2 \\
\hline Wildervanck syndrome & 2 \\
\hline CHARGE syndrome & 2 \\
\hline Oro-facio-digital syndrome & 2 \\
\hline Facio-cardio-renal syndrome & 1 \\
\hline Trisomi 18 & 1 \\
\hline Cornelia de Lange syndrome & 1 \\
\hline Cat eye syndrome & 1 \\
\hline Hay-Wells syndrome & 1 \\
\hline Treacher Collins syndrome & 1 \\
\hline Adams-Oliver syndrome & 1 \\
\hline Velo-Cardio-Facial syndrome & 1 \\
\hline Turner syndrome & 1 \\
\hline Larsen syndrome & 1 \\
\hline Apert syndrome & 1 \\
\hline Fraser syndrome & 1 \\
\hline Gordon syndrome & 1 \\
\hline Klippel Feil syndrome & 1 \\
\hline Goldenhar disease & 1 \\
\hline Dandy-Walker syndrome & 1 \\
\hline Popliteal web syndrome & 1 \\
\hline Total & 1 \\
\hline
\end{tabular}

Pierre Robin sequence constituted the most common group, followed by Van der Woude syndrome and ectrodactyly, ectodermal dysplasia, and clefting syndrome.

In addition to having esthetic deformity, an individual with a cleft lip or palate is exposed to serious functional disorders such as limited maxillofacial growth, speech anomalies, swallowing and nutritional difficulties, and hearing loss. Although not life-threatening, this imposes a significant health burden [5].

\section{Conclusion}

Cleft lip and palate is a multifactorial disease; it is caused by the interaction of genetic factors and environmental factors such as maternal smoking, alcohol consumption, inadequate nutritional intake of folic acid and vitamins B6 and B12, and chemical exposure during pregnancy. Many candidate genes have been and are still being investigated to elucidate the underlying genetic mechanism of cleft lip and palate. A limited knowledge of the regulation of gene expression during palate development in embryogenesis and the mechanism of action of signal molecules does not allow us to precisely identify mutations that lead to cleft lip and palate formation. Molecular studies will contribute to the clarification of the functioning of signaling pathways involved in lip and palate development and thus to a better understanding of cleft lip and palate pathogenesis. In addition, folic acid supplementation during periconceptional period can greatly prevent cleft lip and palate formation. The importance of a rich and balanced diet that includes folic acid as well as other vitamins and minerals should be explained to future mothers in nutrition programs established for preventing cleft lip and palate before conception.

The incidence of cleft lip and palate across the world is generally accepted to be 1 in 1,000 births. However, this incidence is greatly affected by ethnic background, geographical origin, and socioeconomic level. Retrospective studies in Turkey have provided relevant statistical data and reported the incidence of comorbid malformations accompanying cleft lip and palate. In addition to these retrospective studies, detailed and meticulously planned prospective studies may help understand the etiology of the disease more clearly as well as guide researchers working on cleft lip and palate.

\section{References}

1. Carinci F, Scapoli L, Palmieri A, Zollino I, Pezzetti F (2007) Human genetic factors in nonsyndromic cleft lip: An update. Int J Pediatr Otorhinolaryngol 71: 1509-1519. [Crossref]

2. Dixon MJ, Marazita ML, Beaty TH, Murray JC (2011) Cleft lip and palate: understanding genetic and environmental influences. Nature Reviews Genetics 12: 167 178. [Crossref]

3. Stuppia L, Capogreco M, Marzo G, Rovere DL, Antonucci I, et al. (2011) Genetics of syndromic and nonsyndromic cleft lip and palate. J Craniofac Surg 22: 1722-1726. [Crossref]

4. Ağaçayak KS, Ağaçayak E, Coşkun S, Aksoy O (2014) Congenital orofacial clefts Etiology and Frequency. Dicle Med J 41: 429-433.

5. Allam E, Windsor J, Stone C (2014) Cleft Lip and Palate: Etiology, Epidemiology, Preventive and Intervention Strategies. Anatom Physiol Current Res 4: 1-6.

6. Watkins SE, Meyer RE, Strauss RP, Aylsworth AS (2014) Classification, epidemiology, and genetics of orofacial clefts. Clin Plast Surg 41: 149-163.

7. IPDTOC Working Group (2011) Prevalence at birth of cleft lip with or without cleft palate: data from the International Perinatal Database of Typical Oral Clefts (IPDTOC) Cleft Palate Craniofac J 48: 66-81. [Crossref]

8. Brito LA, Cruz LA, Rocha KM, Barbara LK, Silva CBF, et al. (2011) Genetic contribution for non-syndromic cleft lip with or without cleft palate (NS CL/P) in different regions of Brazil and implications for association studies. Am J Med Genet A 155: 1581-1587.

9. Mossey PA, Modell B (2012) Epidemiology of oral clefts 2012: an international perspective. Front Oral Biol 16: 1-18. [Crossref]

10. Beaty TH, Marazita ML, Leslie EJ (2016) Genetic factors influencing risk to orofacial clefts: today's challenges and tomorrow's opportunities. F1000Research 5: 2800. [Crossref]

11. Ulucan K, Akçay A, Ersoy B, Kiraç D, Akçay T, et al. (2012) Regional Dispersion of Non-Syndromic Cleft Lip With/without Palate Turkish Children Patients and Possible Geographical Effects. MÜSBED 2: 164-168.

12. Tunçbilek G, Özgür F, Balci S (2004) Additional malformations and syndromes seen in 1229 cleft lip and palate patients. Çocuk Sağlı̆̆l ve Hastalıkları Dergisi 47: 172-176.

13. Altunhan H, Annagür A, Konak M, Ertuğrul S, Örs R, et al. (2012) The incidence of congenital anomalies associated with cleft palate/cleft lip and palate in neonates in the Konya region, Turkey. Br J Oral Maxillofac Surg 50: 541-544. [Crossref]

14. Yazdy MM, Honein MA, Xing J (2007) Reduction in orofacial clefts following folic acid fortification of the U.S. grain supply. Birth Defects Res A Clin Mol Teratol 79: 16-23. [Crossref]

15. Canfield MA, Collins JS, Botto LD, Williams LJ, Mai CT, et al. (2005) Changes in the birth prevalence of selected birth defects after grain fortification with folic acid in the United States: findings from a multi-state population-based study. Birth Defects Res A Clin Mol Teratol 73: 679-689. [Crossref]

16. Badovinac RL, Werler MM, Williams PL, Kelsey KT, Hayes C (2007) Folic acidcontaining supplement consumption during pregnancy and risk for oral clefts: a metaanalysis. Birth Defects Res A Clin Mol Teratol 79: 8-15. [Crossref]

17. Chevrier C, Perret C, Bahuau M, Zhu H, Nelva A, et al. (2007) Fetal and materna MTHFR C677T genotype, maternal folate intake and the risk of nonsyndromic oral clefts. Am J Med Genet A 143: 248-257. [Crossref]

18. Munger RG, Sauberlich HE, Corcoran C, Nepomuceno B, Daack-Hirsch S, et al (2004) Maternal vitamin B-6 and folate status and risk of oral cleft birth defects in the Philippines. Birth Defects Res A Clin Mol Teratol 70: 464-471. [Crossref]

19. Windsor R (2002) Smoking, cessation and pregnancy. Geneva: World Health Organization. pp: 147-162.

20. Hein DW (2002) Molecular genetics and function of NAT1 and NAT2: role in aromatic amine metabolism and carcinogenesis. Mutat Rese 506-507: 65-77. [Crossref] 
21. Honein MA, Rasmussen SA, Reefhuis J, Romitti PA, Lammer EJ, et al. (2007) Maternal smoking and environmental tobacco smoke exposure and the risk of orofacial clefts. Epidemiology 18: 226-233. [Crossref]

22. Martelli DR, Coletta RD, Oliveira EA, Swerts MSO, Rodrigues LAM, et al. (2015) Association between maternal smoking, gender, and cleft lip and palate. Braz J Otorhinolaryngol 81: 514-519. [Crossref]

23. Mossey PA, Little J, Munger RG, Dixon MJ, Shaw WC (2009) Cleft lip and palate. Lancet 374: 1773-1785. [Crossref]

24. Hillman RS, Steinberg SE (1982) The effects of alcohol on folate metabolism. Annu Rev Med 33: 345- 354. [Crossref]

25. Giovannucci E (2001) Alcohol, one-carbon metabolism, and colorectal cancer: recent insights from molecular studies. J Nutr 134: 2475S-2481S. [Crossref]

26. Meyer KA, Werler MM, Hayes C, Mitchell AA (2003) Low maternal alcohol consumption during pregnancy and oral clefts in offspring: the Slone Birth Defects Study. Birth Defects Res A Clin Mol Teratol 67: 509-514. [Crossref]

27. Molina-Solana R, Yáñez-Vico RM, Iglesias-Linares A, Mendoza-Mendoza A, SolanoReina E (2013) Current concepts on the effect of environmental factors on cleft lip and palate. Int J Oral Maxillofac Surg 42: 177-184. [Crossref]

28. Bille C, Olsen J, Vach W, Andersen AM, Christensen K, et al. (2007) Oral clefts and life style factors a case-cohort study based on prospective Danish data. Eur J Epidemiol 22: 173-181. [Crossref]
29. Kot-Leibovich H, Fainsod A (2009) Ethanol induces embryonic malformations by competing for retinaldehyde dehydrogenase activity during vertebrate gastrulation. Dis Model Mech 2: 295-305. [Crossref]

30. Palmieri A, Avantaggiato A, Marzia Arlotti GB, Luca S, Marcella M, et al. (2008) Drugs and nonsyndromic orofacial cleft: an update. Braz J Oral Sci 7: 1470-1475.

31. Kallen B (2003) Maternal drug use and infant cleft lip/palate with special reference to corticoids. Cleft Palate Craniofac J 40: 624-628. [Crossref]

32. Pradat P, Rober-Gnansia E, Di Tanna G, Rosano A, Lisi A, et al. (2003) First trimester exposure to corticosteroids and oral clefts. Birth Defects Res A Clin Mol Teratol 67: 968-970. [Crossref]

33. Campos Neves AT, Volpato LE, Espinosa MM, Aranha AM, Borges AH (2006) Environmental factors related to the occurrence of oral clefts in a Brazilian subpopulation. Niger Med J 57: 167-172. [Crossref]

34. Garlantézec R, Monfort C, Rouget F, Cordier S (2009) Maternal occupational exposure to solvents and congenital malformations: A prospective study in the general population. Occup Environ Med 66: 456-463. [Crossref]

35. Kawalec A, Nelke K, Pawlas K, Gerber H (2015) Risk factors involved in orofacial cleft predisposition - review. Open Med (Wars) 10: 163-175. [Crossref]

36. Chevrier C, Dananché B, Bahuau M, Nelva A, Herman C, et al. (2006) Occupational exposure to organic solvent mixtures during pregnancy and the risk of non-syndromic oral clefts. Occup Environ Med 63: 617-623. [Crossref]

Copyright: (C2020 Oner DA. This is an open-access article distributed under the terms of the Creative Commons Attribution License, which permits unrestricted use, distribution, and reproduction in any medium, provided the original author and source are credited. 